\title{
Moments in time
}

\author{
Marc Wittmann* \\ Department of Empirical and Analytical Psychophysics, Institute for Frontier Areas in Psychology and Mental Health, Freiburg, Germany
}

\section{Edited by:}

Valerie Doyere, Centre National de la

Recherche Scientifique, France

\section{Reviewed by:}

Valtteri Arstila, University of Turku,

Finland

Bruno Mölder, University of Tartu,

Estonia

\section{${ }^{*}$ Correspondence:}

Marc Wittmann, Institute for Frontier

Areas in Psychology and Mental

Health, Wilhelmstr. 3a, 79098

Freiburg, Germany.

e-mail:wittmann@igpp.de
It has been suggested that perception and action can be understood as evolving in temporal epochs or sequential processing units. Successive events are fused into units forming a unitary experience or "psychological present." Studies have identified several temporal integration levels on different time scales which are fundamental for our understanding of behavior and subjective experience. In recent literature concerning the philosophy and neuroscience of consciousness these separate temporal processing levels are not always precisely distinguished. Therefore, empirical evidence from psychophysics and neuropsychology on these distinct temporal processing levels is presented and discussed within philosophical conceptualizations of time experience. On an elementary level, one can identify a functional moment, a basic temporal building block of perception in the range of milliseconds that defines simultaneity and succession. Below a certain threshold temporal order is not perceived, individual events are processed as co-temporal. On a second level, an experienced moment, which is based on temporal integration of up to a few seconds, has been reported in many qualitatively different experiments in perception and action. It has been suggested that this segmental processing mechanism creates temporal windows that provide a logistical basis for conscious representation and the experience of nowness. On a third level of integration, continuity of experience is enabled by working memory in the range of multiple seconds allowing the maintenance of cognitive operations and emotional feelings, leading to mental presence, a temporal window of an individual's experienced presence.

\section{Keywords: temporal integration, time perception, the present, psychophysics}

The contents of consciousness are phenomenally present - now. This temporal aspect of phenomenal consciousness - its nowness is inherent in all our experiences: I see, hear, feel, and think at the present moment (Metzinger, 2004; Droege, 2009). What is experienced is experienced now. Conscious experience is not static and unchanging; the passage of time is often described by a stream or a flow. Phenomenological analysis has pointed to these two complementary (or seemingly paradoxical) aspects of experience: the feeling of a present moment and the passage of time (James, 1890, chapter XIV; Husserl, 1928). The unity of the present is related to our sense of nowness. The experience of the passage of time constitutes itself through an event that is first anticipated, then experienced and eventually remembered. Taken together, phenomenal consciousness consists of an island of presence in the continuous flow of time related to what is happening right now (Metzinger, 2004).

A debate exists in the philosophical literature surrounding a presumed puzzle of how it is possible to have a temporal experience, to perceive duration, when our experiences are confined to the present moment. If perception is really limited to a present moment then we cannot perceive motion, change, the passage of time (Le Poidevin, 2007). This puzzle is based on the assumption that an observer perceives static snapshots of the world that somehow have to be integrated to form unified experiences over time (Kelly, 2005). A present moment, in this line of thought, is like a mathematical point on a continuum, an isolated and duration-less instant in time. Accordingly, distinct and durationless present moments of experience have to be connected to create phenomenal continuity over time, this conception of time essentially being a cinematographic metaphor. An alternative account of how we perceive change and succession, the flow of time, is that our experiences actually possess inherent temporal properties, i.e., we experience whole intervals in time (Kiverstein, 2010); succession, rhythmic grouping and motion can be directly perceived as constituents of present experience (Stern, 1897). Our momentary experience is embedded in a temporal field reaching both into the past and into the future (Stern, 1897; Lloyd, 2004, 2011). Present experience contains traces of what has just happened and what is anticipated, or in Husserl (1928) terms, the tripartite structure of present experience involves retention, impression, and protention. The perceived present represents its history and possible future, this tripartite structure being an implicit aspect of any conscious experience (Lloyd, 2004, 2011). According to this conception, our present experience is characterized as stretched across time. In different terms, the present moment - as the "specious present" - has duration (James, 1890, chapter XIV). Various conceptualizations have been put forward concerning the experience of an extended present moment. The "retentionalist" view assumes that the contents of momentary experience, although the moment itself is without extension, represent temporally extended intervals; the "extensionalist" position assumes that experiences themselves are defined by temporally extended "chunks." These models are not 
discussed here, but a thorough comparison of the intricate details can be found in Dainton (2010).

The philosophical debate concerning the present moment is mirrored by empirical research in psychology and the neurosciences on the issue of temporal integration of events that constitutes the "psychological present." In fact, recent philosophical contributions refer to the neuroscientific literature of how the brain might integrate events over time; by interpreting empirical findings tentative estimates of characteristic times are provided that are supposed to underlie the experience of the present moment (Pockett, 2003; Kelly, 2005; Callender, 2008; Droege, 2009; Dainton, 2010). The goal of this article is to provide a systematic overview of empirical findings in psychophysics and neuroscience pertaining to temporal integration processes. This article does not aim at contributing to the question concerning the legitimacy of merging phenomenology with neuroscience - bridging the subjective and the objective perspective of the world, essentially the neurophenomenological approach (Varela, 1999; Thompson, 2007). It may be read as presenting knowledge of empirically identified levels of temporal integration that could potentially be assigned to phenomenal experiences of the present moment. However, this is not a philosophical paper but a review of the empirical literature which can be seen as a complementary attempt (from the viewpoint of cognitive neuroscience and psychophysics) to summarize and structure the body of literature on temporal integration as potential correlates of the present moment.

In many independent conceptualizations, perception, cognition, and motor behavior are thought to happen in discrete windows or processing epochs (White, 1963; Pöppel, 1970, 1997; Dehaene, 1993; VanRullen and Koch, 2003). Related specifically to the perception of time, these temporal units have been attributed to a physiological pacemaker or "internal clock" emitting regular pulses (Treisman, 1963). However, it is important to note that the theoretical approach presented here is not primarily concerned with "psychological time" or "explicit judgment of duration." Although empirical findings from research on time perception will be integrated as evidence pertaining to the presented conceptions, the discussed levels of temporal integration are thought to underlie mental processing in general as particularly related to the "present moment." According to these conceptions, successive events are fused into functional units forming snapshots of experience or psychological presents (Ruhnau, 1995; van Wassenhove, 2009). Essentially, temporal experience has no "null point," which would correspond to zero physical duration (Wackermann, 2007). Psychophysical investigations reveal thresholds and minimal durations necessary for certain temporal experiences. Departing from the taxonomy by Pöppel (1997) three different temporal processing levels will be discerned which are assumed to temporally integrate events on different time scales. Each level is discussed to be related to different aspects of the conceptions of a present moment and experienced presence.

\section{THE FUNCTIONAL MOMENT}

The fundamental notion that perception and action are based on discontinuous processing of information in discrete units is characterized by the idea of co-temporality, i.e., events within such a time unit have no before-after relation (Ruhnau, 1995). This is demonstrated by the analysis of psychophysical experiments assessing the perception of successiveness of two events. The sensory systems have different temporal resolutions for the detection of successiveness or non-simultaneity. The highest temporal resolution (the lowest threshold of detection) is observed in the auditory system, where two short acoustic stimuli which are only 2-3 ms apart are detected as non-simultaneous. The visual and the tactile system have a lower temporal resolution with respect to non-simultaneity with thresholds of some tens of milliseconds; inter-modal stimulation leads to the highest thresholds (Exner, 1875; Lackner and Teuber, 1973; Kirman, 1974; Lotze et al., 1999). The detection of non-simultaneity of two short events, however, is not perceptually sufficient to indicate their temporal order. Although we may be aware that two events did not occur simultaneously, we can still be unable to tell which one of the two stimuli occurred first. The temporal order threshold, which defines the inter-stimulus interval between two events at which an observer can reliably indicate the temporal order is more comparable across senses and lies roughly at 20-60 ms, to some extent depending on physical stimulus properties (Hirsh and Sherrick, 1961; Fink et al., 2006a; Miyazaki et al., 2006; Szymaszek et al., 2009). A similar minimal threshold of at least $20 \mathrm{~ms}$ is necessary for the identification of temporal order of onset between two longer complex acoustic events, adding to the notion that the temporal-order threshold marks a fundamental limit of temporal perception (Pastore and Farrington, 1996).

Temporal order is a primary experiential temporal datum, connecting subjective experience with the objective order of events (Wackermann, 2007, 2008). Ultimately, the notion of time is based on the elementary temporal relation of two events, $A$ and $B$, which can be judged in their temporal order, " $A$ occurs before $B$ " or " $A$ occurs after $B$." For example, music and spoken language are only meaningful if the correct temporal order of individual components is detected. The inversion of temporal order would lead to a different and new experience. For this reason, experienced temporal order as retrieved from memory appears in the same temporal order as when it was perceived (Mach, 1911). Below the experimentally assessed threshold of some tens of milliseconds the temporal order of events cannot be reliably detected. Elements that are perceived as non-simultaneous can be inter-changed without a noticeable effect for an observer. This has, for example, lead to the idea that temporal information within a segment of the speech signal not exceeding the functional moment might not be relevant for decoding spoken language (Kiss et al., 2008). The relation between the perception of speech and the perception of temporal order has repeatedly been demonstrated in studies with neurological patients suffering from aphasia and with adolescents who have language-learning impairments (Wittmann and Fink, 2004). These individuals have difficulties in discriminating consonants, which requires the ability to detect temporal order of speech signal components, because they have increased auditory temporal order thresholds (Wittmann et al., 2004; Fink et al., 2006b).

Based on the empirical findings of discrete processing in perception and action it has therefore been suggested that the brain creates a-temporal system states during which incoming information is treated as co-temporal, and which are on the one hand responsible for binding intra- and inter-modal information and 
on the other hand create the experience of temporal order (Pöppel et al., 1990; Ruhnau, 1995; Pöppel, 1997). The idea that perceptual information as well as motor commands might be processed in discrete packets, at regular moments in time (Dehaene, 1993; VanRullen and Koch, 2003; van Wassenhove, 2009), is in accordance with the conception of a functional moment, a snapshot of perception. Findings of several independent empirical approaches in neuroscience have lead to the suggestion that temporal building blocks in sensory and cognitive processing exist - responsible for creating discrete functional units in time as well as binding spatial features into perceptual wholes. These temporal units have been related to rhythmic brain activity of thalamo-cortical loops, the "gamma" band with a frequency of around $40 \mathrm{~Hz}$ (Joliot et al., 1994; Basar-Eroglu et al., 1996; Fries et al., 2007; Ehm et al., 2011). However, periodicities in the alpha band (around $10 \mathrm{~Hz}$ ) as well as the theta band $(4-8 \mathrm{~Hz})$, and potentially related to functional integration on a time scale of $100 \mathrm{~ms}$ and above (see below), may additionally contribute to temporal integration phenomena (VanRullen and Koch, 2003; van Wassenhove, 2009).

It is important to note that basic temporal integration mechanisms uniting disparate events into perceptual segments have been identified on different time scales and also in more complex inter-sensory perceptual tasks. For example, a time frame of about $200 \mathrm{~ms}$ determines the integration of auditory-visual input in speech processing when probing for the McGurk effect - an illusory fusion percept created when lip movements are incongruent to heard syllables (van Wassenhove et al., 2007). The fusion percept was reported if the onset of lip movement and syllable did not exceed this time lag. Temporal integration in a time frame of around $250 \mathrm{~ms}$ was reported in sensory-motor processing distinguishing maximum tapping speed from a personal, controlled motor speed (Peters, 1989; Wittmann et al., 2001). With repetitive finger movements such as with maximum tapping speed, when inter-tap intervals are around $150 \mathrm{~ms}$, movements are too fast to be represented as individual button presses within an ordered sequence. Only when the movement slows down and inter-tap intervals exceed at least $250 \mathrm{~ms}$ individuated button presses are experienced as following each other. Stimulus durations of 200$300 \mathrm{~ms}$ (and minimum inter-onset intervals) are a necessary prerequisite for the establishment of temporal order representation for the detection of the correct sequence of four acoustic or visual events (Warren and Obusek, 1972; Ulbrich et al., 2009). When stimuli are shorter, or the inter-onset between stimuli is smaller, subjects cannot reliably report the temporal order of the presented sequence. An interpretation of these finding is that if two or more stimulus onsets fall within one window of temporal integration then temporal order cannot be experienced as the onsets are treated as co-temporal.

Regarding this approximate time range, it has been proposed that anterior insular cortex function may provide the continuity of subjective awareness by temporally integrating a series of elementary building blocks - successive moments of self-realization informed by the interoceptive system (Craig, 2009). The continuous processing from moment to moment would advance with a frame rate of about $8 \mathrm{~Hz}$, these temporal building blocks of perception lying in the range of $125 \mathrm{~ms}$ (Picard and Craig, 2009). Neural microstates with average duration of $125 \mathrm{~ms}$ as derived from electrophysiological recordings have been discussed as potential "atoms of thought," constituting critical time windows within which neural events are functionally integrated (Lehmann et al., 1998). In combining the two kinds of functional moments presented here, endogenous cortical rhythms in the gamma and theta range involved in speech perception and production have been related to corresponding left- and right-hemispheric neural activation. Speech would be processed by the left auditory cortex, integrating the signal into $20-60 \mathrm{~ms}$ segments which would correspond to phoneme length; at the same time speech would be processed in the right auditory cortex, integrating the signal into segments of 100-300 ms corresponding to syllabic analyzes (Poeppel, 2003; Giraud et al., 2007). In the context of findings of various temporal integration phenomena it has moreover been proposed that mental processing is organized in multiple ranges of discrete periods which are all multiples of an absolutely smallest quantal period estimated to lie at approximately $4.5 \mathrm{~ms}$ (Geissler and Kompass, 2003).

It has to be noted that research has identified further integration phenomena, all being on comparable time scales (Fraisse, 1984). For example, a temporal integration window of $100-150 \mathrm{~ms}$ duration has been suggested to operate for perceptual grouping mechanisms of target and distractor tones in sensori-motor processing (Repp, 2004). Using the paradigm of mismatch negativity of magnetic brain responses a window of integration of $160-170 \mathrm{~ms}$ was estimated to bind successive auditory input into an auditory percept (Yabe et al., 1998). Further integration levels below $1 \mathrm{~s}$ as related to the processing of static stimuli as well as associated with motion perception are not presented, but see Fraisse (1984) and Dainton (2010). Potentially, many other kinds of basic functional moments may exist. ${ }^{1}$ What these divergent findings have in common is that on a temporally fine grained level in the range of tens of milliseconds as well as of hundreds of milliseconds temporal integration phenomena occur that are the basis for the experience of temporal unity of events (below the threshold) and of succession and temporal order (above the threshold). Below the reported thresholds of around $30 \mathrm{~ms}$ (when two short events are presented) or of thresholds ranging between 100 and $300 \mathrm{~ms}$ (when a stream of events is presented) temporal integration provides functional moments of experienced co-temporality. One could argue that these functional moments, within which events are fused together, are not experienced as having duration. Although the sensation of non-simultaneity implies two temporally separated events, one could nevertheless say that the experience of duration necessitates a clearly demarcating onset $A$ and offset $B$ defining an interval (with the inherent temporal order $A$ before $B$ ). In this sense one can state that below the temporal order threshold, when two events have no clear temporal relation, subjective duration between the two stimuli is not experienced; the functional moment has no perceivable duration.

\section{THE EXPERIENCED MOMENT}

Despite the possibly discrete nature of underlying processes in perception and cognition, our phenomenal experience is nevertheless

${ }^{1}$ On the level of the functional moment the concepts of prediction (van Wassenhove et al., 2005) and postdiction (Eagleman and Sejnowski, 2000) could be discussed. 
characterized as evolving continuously (VanRullen and Koch, 2003). Only in rare neurological disorders or under the influence of pharmacological agents such as LSD individuals occasionally report of perceiving a series of discrete stationary images (Dubois and VanRullen, 2011). However, we typically do not perceive static snapshots of the world but perceived events are embedded in an ongoing stream of experience. Music and language are only conceivable as consisting of extended moments, melodies, and phrases, which inter-connect individual musical and linguistic elements (Wittmann and Pöppel, 2000). Even when we focus on an individual note in a musical piece or a word in a spoken sentence, these acoustic events can only be understood in its temporal relation to the preceding and the following musical or language structure. It is impossible to ignore the temporal context of what we perceive. Lloyd $(2004,2011)$ has an intuitive example for temporality in music: when we hear Paul McCartney land on "Jude," the "Hey" is still somehow present although no longer sensed (Husserl's retention). A listener familiar with the Beatles, when she hears the "Hey" cannot help but already hear the "Jude." The "Jude" is somehow present but it is actually only anticipated (Husserl's protention). In phenomenological terms, what we perceive at present is strongly intertwined with what has just happened and what is about to happen (Lloyd, 2004, 2011; Kiverstein, 2010).

When listening to a metronome at moderate speed, we do not hear a train of individual beats, but automatically form perceptual gestalts as an accent is perceived on every $n$th beat (1-2, $1-2$, or $1-2-3,1-2-3)$. These temporal units are mental constructs - physically speaking, they do not exist (Pöppel, 2009). If the metronome is too fast, the inter-beat intervals are very short, a fast train of beats is perceived that cannot be experienced as containing temporally separated events with an ordered temporal structure. Subjective accentuation is not possible. If on the other hand the metronome is too slow, inter-beat intervals are too long, only individual beats which are not related to each other are perceived (1-1-1 etc.). This lower and upper range of the metronome speed at which accentuated temporal structures can be heard defines the temporal limits of perceptual grouping on this time scale. Empirical evidence suggests that these mental units comprising several individual beats have a lower limit of around $250 \mathrm{~ms}$ and an upper limit of approximately $2 \mathrm{~s}$ (Szelag et al., 1996; von Steinbüchel et al., 1999; London, 2002). Further empirical observations revealed through a systematic variation of duration indicate that empty intervals marked by two acoustic events larger than $150-250 \mathrm{~ms}$ and shorter than $2 \mathrm{~s}$ are perceived as qualitatively different than intervals beyond these temporal boundaries (Benussi, 1913; Nakajima et al., 1980). For example, two sound bursts separated by an interval below $150 \mathrm{~ms}$ were perceived as one double-peaked sound; between $150 \mathrm{~ms}$ and $2 \mathrm{~s}$ the two sound bursts were clearly separated from each other but subjects still felt a relation between them and they tried to automatically synchronize their body movements to the stimulus pair; with intervals larger than $2 \mathrm{~s}$ subjects reported that the two sounds were difficult to relate to each other and synchronization of body movements was not attempted (Nakajima et al., 1980). Whereas findings of qualitative as well as quantitative differences between intervals below and above $2 \mathrm{~s}$ are predominantly found by presenting empty intervals that are marked by two sounds (for a psychophysical study see Getty, 1975), also regarding filled intervals it has been shown that duration up to $2-3 \mathrm{~s}$ is differently processed than duration exceeding $3 \mathrm{~s}$ (Ulbrich et al., 2007). However, results are not as clear cut as with empty intervals and "break points" are not always found (Noulhiane et al., 2008; Lewis and Miall, 2009). Temporal segmentation has been reported in further investigations in sensory-motor control. Subjects can synchronize their motor actions to a sequence of presented tones with inter-stimulus intervals of above $250 \mathrm{~ms}$ (Peters, 1989). However, this synchronization ability can only be maintained when inter-tone intervals do not exceed durations of about 2-3 s. With longer intervals precise anticipation of tones - effortless timing of behavior - breaks down (Mates et al., 1994). In a further analysis of this type of timing behavior, time ranges between 0.45 and $1.5 \mathrm{~s}$ seemed to be processed automatically, i.e., not strongly affected by secondary task fulfillment, whereas concomitant processing of a secondary task affected intervals in the range between 1.8 and 3.6 s (Miyake et al., 2004).

Also the phenomenon of perceptual bi-stability suggests itself for studying temporal constraints of conscious experience as one can easily tap into the subjective percepts (Leopold et al., 2002; van Ee, 2005). The temporal analysis of bi-stable perception has been suggested as primary experimental approach for the understanding of the dynamics of mental states (Atmanspacher and Filk, 2010). In essence, an ongoing competition between the neural representations of the two aspects of an ambiguous figure, such as the Necker cube, has to be resolved leading to the experience of one of the two perspectives at a given point in time. During continuous presentation, one aspect lasts on average for around $3 \mathrm{~s}$ before a switch in perspectives occurs, with some inter-individual variability and variance attributable to stimulus characteristics of the particular ambiguous figure (Gómez et al., 1995; von Steinbüchel et al., 1999; Meng and Tong, 2004; Kornmeier et al., 2007). Given its temporal dynamics, the spontaneous switching rate has been discussed as stemming from the discussed temporal segmentation mechanism related to the subjective present (Varela, 1999; Franck and Atmanspacher, 2009; Pöppel, 2009).

The experienced moment can be related to more elementary units of perception. For example, it has been proposed that the temporal integration mechanism of around $3 \mathrm{~s}$, evoking our feeling of nowness, integrates successive processing units of around $30 \mathrm{~ms}$, functional moments (Pöppel, 1997, 2009; Szelag et al., 2004). In another line of research that treats bi-stable perception as evolving from unstable two-state systems it was proposed that different mental processing stages have temporal properties matching the found temporal integration levels of 30, 300, and $3 \mathrm{~s}$ (Atmanspacher et al., 2004; Atmanspacher and Filk, 2010). In combining the empirical findings, temporal integration of a few seconds has been suggested to provide the logistical basis for the subjective present (Pöppel, 1978, 2009; Fraisse, 1984; Szelag et al., 2004). Whereas the duration of the functional moment is not perceived, an experienced moment relates to the experience of an extended now. According to this conception, the experienced moment has duration. 


\section{MENTAL PRESENCE}

A temporal interval with duration exceeding about $3 \mathrm{~s}$ is experienced as being qualitatively different than shorter duration. When two events are separated by an interval of, say, $6 \mathrm{~s}$, the experience of "emptiness" evolves, events are not bound together and the length of the interval separating the two becomes the focus of attention (Wackermann, 2007). A pause in a conversation, if it reaches $6 \mathrm{~s}$, might be felt as disturbingly long. In that sense, duration longer than $3 \mathrm{~s}$ leads to the predominant experience of an extended temporal interval. On the other side of the spectrum, what is the maximum time interval an observer can directly experience? It is well possible to judge the duration of $1 \mathrm{~h}$, i.e., pressing a button every time one thinks that an hour has passed (Aschoff, 1998). However, it is impossible to maintain a 1-h time interval continuously in the focus of awareness (Wackermann, 2007). During such a period of $1 \mathrm{~h}$ a multitude of experiences accumulates that later can be retrieved from memory forming temporal cues that can be used to judge duration retrospectively (Zakay and Block, 1997). But then the question remains what the upper limit of integration in prospective time perception might be, that is, of the perception of duration as presently and continuously experienced? More generally formulated and more importantly, what are the temporal boundaries of perception that allow us to hold events in present experience, in mental presence? Whereas the experienced moment forms an elementary unit, a temporally unified percept, mental presence involves the experience of a perceiving and feeling agent ("my self") within a window of extended presence, a phenomenon that is based on working memory function. "Working memory provides a temporal bridge between events - both those that are internally generated and environmentally presented - thereby conferring a sense of unity and continuity to conscious experience" (GoldmanRakic, 1997). An experienced moment happens now, for a short but extended moment. Mental presence encloses a sequence of such moments for the representation of a unified experience of presence.

Reports from neurological case studies with individuals who suffer from anterograde amnesia after bilateral damage to the hippocampus indicate that these patients live within a moving temporal window of presence that does not reach beyond their short-term or working memory span, incapable of storing incidents into episodic long-term memory (Scoville and Milner, 1957). These patients can hold information for a limited time in memory, they perform short tasks accurately and seemingly behave normal; but already after a few minutes they can not recall what has just happened (for a striking description of a patient with anterograde amnesia, see Sacks, 1986). Due to their neurological impairment, patients with anterograde amnesia can act adequately within the temporal constraints of their functioning working memory, which accordingly must be a temporal constraint for mental presence, the continuous awareness of oneself as presently perceiving and acting within an environment. These clinical cases emphasize the functioning of short-term memory in healthy humans and how it can be interpreted as forming temporal boundaries of present awareness.

Experimental investigations of short-term memory show how the number of correct recalls of presented syllables decreases with increasing interval length between stimulus presentation and recall - in the range of multiple seconds - if the rehearsal of syllables is prevented (Peterson and Peterson, 1959; Baddeley, 1990). The capacity of short-term retention is defined as gradual loss of memorized elements as time passes. The typical retention functions described by logarithmic and exponential fits decrease rapidly at first and then levels out on a plateau (Rubin and Wenzel, 1996). One could state that the time frame provided by short-term memory (related, working memory) creates a temporal horizon of experience which in humans contains descriptive-narrative elements created by our capacity for language (Varela, 1999). Within this temporal horizon mental presence unfolds integrating mental processes and enabling conscious experience of a narrative self that has personal identity and continuity over time (Gallagher, 2000). Mental presence is bound to the ability of maintaining mental representations in an active state for a certain period of time. It depends on the integration of multiple mental operations that lead to intentional behavior - created by ongoing activity of a global workspace, integrating activity from multiple distributed and specialized brain areas (Baars, 1988; Dehaene and Naccache, 2001). Essentially, it is working memory, a system of limited attentional capacity, supplemented by visuospatial, episodic, and phonologic storage systems, which holds information for temporal storage and manipulation (Baddeley, 2003).

In duration reproduction tasks, individuals have to reproduce temporal intervals by pressing a key to indicate that a second comparison stimulus has reached the duration of a previously presented stimulus. The mean of reproduced intervals is accurate for shorter intervals of up to $3 \mathrm{~s}$ but with increasing interval lengths are progressively under-reproduced relative to physical time (Eisler and Eisler, 1992; Wackermann, 2005; Ulbrich et al., 2007; Wittmann et al., 2010). The negative curvature of the duration reproduction function results in an asymptotic upper limit of duration accessible to experience, i.e., a temporal horizon of experienced time in the range of roughly $10^{2} \mathrm{~s}$ (Wackermann, 2007). Note, that the negative curvature in duration reproduction performance is found in those studies where subjects are instructed or discouraged from counting (Rattat and Droit-Volet, 2011). Without chronometric counting, the immediate experience of duration is limited by an ultimate temporal horizon of reproducibility due to memory-loss of duration representation over time; temporal resolution of duration blurs with increasing interval length (Wackermann, 2007, 2008). ${ }^{2}$ It is tempting to suggest that a healthy individual's short-term memory span is related to the upper limit of prospective time perception; the limits of temporal experience, of perceiving duration continuously, would

\footnotetext{
${ }^{2}$ A famous patient with anterograde amnesia, H.M., as studied by Richards (1973) was supposedly found to show an impaired performance in duration reproduction at longer time intervals. This claim, however, is not substantiated by the available data (Wackermann, personal communication). When plotting the behavioral data of H.M. as absolute values, extracted by Eisler and Eisler (2001), and not as log-log plots one can see a perfect asymptotic curve for stimulus durations ranging from 1 to $300 \mathrm{~s}$. A parametric fit using the 'dual klepsydra model' (Wackermann and Ehm, 2006) revealed that parameter $\kappa$, reflecting the progressive under-reproduction of duration, with $0.011 \mathrm{~s}^{-1}$ is in a typical range of adult subjects (Wackermann, 2005). That is, H.M. was able to time his behavior adequately within the time range of his mental presence.
} 
thereafter rely on the basic temporal properties of working memory. In fact, decay of memory traces has been discussed to underlie the experience of duration. Since memory strength decreases with time, memory trace decay could actually function as a "clock" (Staddon, 2005). That way, the same processes would underlie forgetting as well as time perception. This memory-loss component is an intrinsic feature of the "dual klepsydra model" (Wackermann and Ehm, 2006; Wackermann, 2008), where subjective duration is represented by the state of a lossy accumulator. This accumulator receives inflow for the build-up of duration presentation of a stimulus that has to be judged. A simultaneous outflow reflects the loss of representation leading to typical responses in psychophysical tasks, indicative of "subjective shortening" of stored duration over time.

There is no absolute, fixed temporal boundary of mental presence. The reports of a limiting value in the order of magnitude of $10^{2} \mathrm{~s}$ in the ability to reproduce duration indicate that the representation of increasing duration becomes more and more compressed. The duration reproduction curve becomes increasingly flatter, i.e., with increasing temporal intervals differences in physical duration are represented with decreasing resolution (Wackermann, 2007).

That is, the reported limits in duration reproduction and shortterm memory do not point to absolute and static boundaries correspondingly, mental presence has no fixed duration - but to a gradual dissolving of representation with increasing duration. Related to this temporal characteristic, mental presence is related to the fact that once attended objects slowly phase out of experience over time; that is, the phenomenally experienced sliding window of mental presence co-occurs with the constant loss of memory contents. The moving window of presence is related to the constant sequential input of a sequence of perceived events, which each fade out of working memory one after the other after some time. Mental presence is a temporal platform of multiple seconds within which an individual is aware of herself and the environment, where sensory-motor perception, cognition, and emotion are interconnected features of representation leading to phenomenal experience.

\section{CONCLUSION}

Facing the puzzle of how we can perceive duration of events if our perception is bound to the present moment, more than 1600 years ago St. Augustine gave an answer (Flasch, 1993). Although the present (praesens tempus) has no extension as it passes away in a moment (in puncto praeterit), an observation nevertheless has extension (distentio) through temporally lasting attention (attentio) which encompasses the anticipation of events (expectatio) that eventually fade into memory (memoria); here, anticipation and memory are part of an extended present where attention lasts for some time (Confessions, book XI; section XXVIII.37 in Flasch, 1993). Moreover, conscious experience involving a sense of self may only be understood as an entity that is extended over time (Zahavi, 2005; Wittmann, 2009; Stolzenberg, 2010). It is obvious that St. Augustine's conception of time has strong similarities to Husserl (1928) tripartite structure of present experience. Although a variety of philosophical models concerning the present moments exists, important in the present context is the common insight that the present moment is experienced as extended. Also our everyday language use implies that what is happening at the present moment typically has duration. ${ }^{3}$

Present experience on the level of content is a continuously evolving phenomenon and individual events are embedded in an extended temporal field (Stern, 1897; Lloyd, 2004, 2011). A suddenly occurring short stimulus of a few milliseconds might actually be perceived as a point in time. Moreover, psychophysical investigations in which stimulus properties are systematically varied reveal thresholds of experience below which no temporal relationship is perceived. In these limiting cases disclosed by psychophysics one can actually speak of functional moments without perceivable duration because temporal order, a primary experiential datum, is not detected. This single momentary event is nevertheless part of a continuous and extended experience. For example, if a short tone with a lower pitch is followed by another short tone with a slightly higher pitch, the impression of a single tone rising in pitch can be elicited (Fink et al., 2006a). Within different modalities, the rapid serial appearance of two or more stimuli at different positions can give the impression of apparent motion (Exner, 1875; Kirman, 1974). That is, the common cases of perception, in accordance with the phenomenological analysis of our Lebenswelt, suggest that subjective time provides a frame of reference within which moments are stretched out over time.

The integration level of the experienced moment is the basic operational platform within which temporality can evolve. The unit that the first two words in the Beatles lyrics "Hey Jude" form, as short as the overall duration may seem, involves anticipation and memory which are activated while the "Hey" passes over to "Jude" (Lloyd, 2004, 2011). After having heard "Hey Jude" some people might even anticipate the "...don't make it bad." Then, however, the two verses may already fall into two different experienced moments. The break between the two subunits "Hey Jude" and “... don't make it bad" points to a general principle in poems and in music where caesurae form boundaries between which individual verses are recited; across different languages and cultures the duration of these lyrical and musical units seems not to exceed 3s (Pöppel, 1988; Turner and Pöppel, 1988). Beyond the experienced moment successive events are less strongly bound together. "Hey Jude" is a stronger bounded unit than "Hey Jude, don't make it bad." And with increasingly longer intervals temporally separate components within these units will become less strongly connected; retention and protention are temporally limited in the way that they cover only what has just happened and is about to happen in the range of a few seconds, working memory span forming a boundary of present experience as mental presence. The discussed examples in literature of experienced temporality refer to situations concerning temporal integration in the several seconds range. Husserl (1928, p. 383) discusses the situation of hearing a melody which is only possible because individual tones are integrated to form a perceptual whole. Kelly (2005) presents the example of hearing a steady high $\mathrm{C}$ produced by an opera singer

\footnotetext{
${ }^{3}$ When J. W. Goethe's Faust proclaims: "When, to the Moment then, I say: Ah, linger on, thou art so fair!" ("Werd ich zum Augenblicke sagen: Verweile doch! Du bist so schön!”), he definitely refers to an extended moment that he would like to see prolonged indefinitely.
} 
who holds that note for some time - for the listener subjectively going on for a long time - that is, for several seconds.

Different from this phenomenological notion of retention and protention is the conception of time perspective as a fundamental cognitive dimension partitioning human experience into past, present, and future (Zimbardo and Boyd, 1999). Past and future in this context can span decades, as far as long-term memory reaches back in time and as far as we plan our future. Through this partitioning of time, the notion of a presence becomes meaningful since the explicit representation of the present perspective is only possible through its distinction from past and future (Droege, 2009). Within the realm of the mental presence an individual can be considered fully operational as she tracks current conditions, compares them with memories of past incidences, and makes plans for the future. The past and the future as presently experienced can also be explicitly judged in relation to subjective time. When judging the past, we typically perceive the decades of our lives to speed up as we get older (Wittmann and Lehnhoff, 2005). Related to the future, we constantly generate predictions about how long it will take for some events to occur, these temporal estimates eventually leading to decisions regarding options with different delays (Wittmann and Paulus, 2009). For example, a person who chooses to save money opts for a momentary loss of money that otherwise would be available now in order to gain a future greater benefit.

A fundamental question remains of how lower-level temporal units are bound together forming higher-level units; a variety of concepts has been rigorously discussed by Dainton (2010). Independent of how the sequential units of lower-level units might be related to each other, potentially overlapping each other or following in direct succession, continuity of experience has been considered to stem from an ongoing semantic connection

\section{REFERENCES}

Aschoff, J. (1998). Human perception of short and long time intervals: its correlation with body temperature and the duration of wake time. J. Biol. Rhythms 13, 437-442.

Atmanspacher, H., and Filk, T. (2010). A proposed test of temporal nonlocality in bistable perception. J. Math. Psychol. 54, 314-321.

Atmanspacher, H., Filk, T., and Römer, H. (2004). Quantum Zeno features of bistable perception. Biol. Cybern. 90, 33-40.

Baars, B. J. (1988). A Cognitive Theory of Consciousness. Cambridge: Cambridge University Press.

Baddeley, A. (1990). Human Memory. Theory and Practice. Boston: Allyn and Bacon.

Baddeley, A. (2003). Working memory: looking forward and looking back. Nat. Rev. Neurosci. 4, 829-839.

Basar-Eroglu, C., Strueber, D., Schuermann, M., Stadler, M., and Basar, E. (1996). Gamma-band responses in the brain: a short review of psychophysiological correlates and functional significance. Int. J. Psychophysiol. 24, 101-112.

Benussi, V. (1913). Psychologie der Zeitauffassung. Heidelberg: Carl Winters Universitätsbuchhandlung.

Callender, C. (2008). The common now. Phil. Issues 18, 339-361.

Craig, A. D. (2009). How do you feel now? The anterior insula and human awareness. Nat. Rev. Neurosci. 10, 59-70.

Dainton, B. (2010). "Temporal consciousness," in The Stanford Encyclopedia of Philosophy, ed. E. N. Zalta. Available at: http://plato.stanford. edu/archives/fall2010/entries/consci ousness-temporal

Dehaene, S. (1993). Temporal oscillations in human perception. Psychol. Sci. 4, 264-270.

Dehaene, S., and Naccache, L. (2001). Towards a cognitive neuroscience of consciousness: basic evidence and a workspace framework. Cognition 79, $1-37$.

Droege, P. (2009). Now or never: how scious. Cogn. 18, 78-90. consciousness represents time. Con-

across individual segments, which masks the discontinuity of the sequential units (Pöppel, 1997; Droege, 2009). Regarding specifically the continuity of experience across experienced moments, working memory related to semantic and episodic content might bind together the sequence of temporal segments of nowness that leads to the experience of mental presence. The experienced moment is defined as what is occurring now as immediate experience. It is also a prerequisite for interpersonal communication between two individuals made possible by synchronizing the moments of individuals, thereby creating shared moments of presence for effortless interaction - an essential feature in music, conversation, and dance (Wittmann and Pöppel, 2000). However, the experience of a self acting in its environment, remembering the past and planning the future necessitates an integration interval - as has been related to mental presence exceeding the postulated 3-s time window of the experienced moment. Continuity of experience only unfolds as mental presence, which is a floating window of feeling present and acting at present.

\section{ACKNOWLEDGMENTS}

This work has been supported by the European project COST ISCH Action TD0904 "Time In MEntaL activitY: theoretical, behavioral, bioimaging, and clinical perspectives (TIMELY; www.timely-cost.eu)." Over the years, the author's research was supported by the Bundesministerium für Bildung und Forschung, Germany, the Max Kade Foundation, New York, The National Institute on Drug Abuse, Bethesda, and the Kavli Institute for Brain and Mind, San Diego. I would like to thank Jirí Wackermann, Jürgen Kornmeier, Harald Atmanspacher as well as the two reviewers for helpful comments on the manuscript.

Dubois, J., and VanRullen, R. (2011). Visual trails: do the doors of perception open periodically? PLoS Biol. 9, e1001056. doi:10.1371/journal.pbio. 1001056

Eagleman, D. M., and Sejnowski, T. J. (2000). Motion integration and postdiction in visual awareness. Science 287, 2036-2038.

Ehm, W., Bach, M., and Kornmeier, J. (2011). Ambiguous figures and binding: EEG frequency modulations during multistable perception. Psychophysiology 48, 547-558.

Eisler, H., and Eisler, A. D. (1992). Time perception: effects of sex and sound intensity on scales of subjective duration. Scand. J. Psychol. 33, 339-358.

Eisler, H., and Eisler, A. D. (2001). Subjective time in a patient with neurological impairment. Psychologica 28, 193-206.

Exner, S. (1875). Experimentelle Untersuchung der einfachsten psychischen Prozesse. III. Abhandlung. Pflug. Arch. Ges. Physiol. 11, 403-432.
Fink, M., Ulbrich, P., Churan, J., and Wittmann, M. (2006a). Stimulusdependent processing of temporal order. Behav. Processes 71, 344-352.

Fink, M., Churan, J., and Wittmann, M. (2006b). Temporal processing and context dependency of phoneme discrimination in patients with aphasia. Brain Lang. 98, 1-11.

Flasch, K. (1993). Was ist Zeit? Augustinus von Hippo. Das XI. Buch der Confessiones. Frankfurt am Main: Vittorio Klostermann.

Fraisse, P. (1984). Perception and estimation of time. Annu. Rev. Psychol. $35,1-36$.

Franck, G., and Atmanspacher, H. (2009). "A proposed relation between intensity of presence and duration of nowness," in Recasting Reality. Wolfgang Pauli's Philosophical Ideas and Contemporary Science, eds H. Atmanspacher and H. Primas (Berlin: Springer), 211-225.

Fries, P., Nikolic, D., and Singer, W. (2007). The gamma cycle. Trends Neurosci. 30, 309-316. 
Gallagher, S. (2000). Philosophical conceptions of the self: implications for cognitive science. Trends Cogn. Sci. 4, 14-21.

Geissler, H.-G., and Kompass, R. (2003). "Invariants in mental timing: from taxonomic relations to task-related modelling," in Time and Mind II, ed H. Helfrich (Göttingen: Hogrefe \& Huber), 185-207.

Getty, D. J. (1975). Discrimination of short temporal intervals: a comparison of two models. Percept. Psychophys. 18, 1-8.

Giraud, A.-L., Kleinschmidt, A., Poeppel, D., Lund, T. E., Frackowiak, R. S. J., and Laufs, H. (2007). Endogenous cortical rhythms determine cerebral specialization for speech perception and production. Neuron 56, 1127-1136.

Goldman-Rakic, P. (1997). Space and time in the mental universe. Nature $386,559-560$.

Gómez, C., Argandoa, E. D., Solier, R. G., Angulo, J. C., and Vázquez, M. (1995). Timing and competition in networks representing ambiguous figures. Brain Cogn. 29, 103-114.

Hirsh, I. J., and Sherrick, C. (1961). Perceived order in different sense modalities. J. Exp. Psychol. 62, 423-432.

Husserl, E. (1928). Vorlesungen zur Phänomenologie des inneren Zeitbewußtseins. Halle: Max Niemeyer Verlag.

James, W. (1890). The Principles of Psychology. London: MacMillan.

Joliot, M., Ribary, U., and Llinás, R. (1994). Human oscillatory brain activity near $40 \mathrm{~Hz}$ coexists with cognitive temporal binding. Proc. Natl. Acad. Sci. U.S.A. 88, 4966-4970.

Kelly, S. (2005). "The puzzle of temporal experience," in Cognition and the Brain: The Philosophy and Neuroscience Movement, eds A. Brook and K. Akins. (Cambridge: Cambridge University Press), 208-238.

Kirman, J. H. (1974). Tactile apparent movement: the effects of number of stimulators. J. Exp. Psychol. 103, 1075-1080.

Kiss, M., Cristescu, T., Fink, M., and Wittmann, M. (2008). Auditory language comprehension of temporally reversed speech signals in native and non-native speakers. Acta Neurobiol. Exp. (Wars) 68, 204-213.

Kiverstein, J. (2010). Making sense of phenomenal unity: an intentionalist account of temporal experience. $R$. Inst. Philos. Suppl. 85, 155-181.

Kornmeier, J., Ehm, W., Bigalke, H., and Bach, M. (2007). Discontinuous presentation of ambiguous figures: how interstimulus-interval durations affect reversal dynamics and ERPs. Psychophysiology 44, 552-560.

Lackner, J. R., and Teuber, H.J. (1973). Alterations in auditory fusion threshold after cerebral injury in man. Neuropsychologia 11, 409-415.

Le Poidevin, R. (2007). The Images of Time. An Essay on Temporal Representation. Oxford: Oxford University Press.

Lehmann, D., Strik, W. K., Henggeler, B., Koenig, T., and Koukkou, M. (1998). Brain electric microstates and momentary conscious mind states as building blocks of spontaneous thinking: I. Visual imagery and abstract thoughts. Int. J. Psychophysiol. 29, 1-11.

Leopold, D. A., Wilke, M., Maier, A., and Logothetis, N. K. (2002). Stable perception of visually ambiguous patterns. Nat. Neurosci. 5 605-609.

Lewis, P. A., and Miall, R. C. (2009). The precision of temporal judgement: milliseconds, many minutes, and beyond. Philos. Trans. R. Soc. Lond. B Biol. Sci. 364, 1897-1905.

Lloyd, D. (2004). Radiant Cool. A Novel Theory of Consciousness. Cambridge, MA: The MIT Press.

Lloyd, D. (2011). Neural correlates of temporality: default mode variability and temporal awareness. Conscious. Cogn. doi: 10.1016/ j.concog.2011.02.016. [Epub ahead of print].

London, J. (2002). Cognitive constraints on metric systems: some observations and hypotheses. Music Percept. 19, 529-550.

Lotze, M., Wittmann, M., von Steinbüchel, N., Pöppel, E., and Roenneberg, T. (1999). Daily rhythm of temporal resolution in the auditory system. Cortex 35, 89-100.

Mach, E. (1911). Die Analyse der Empfindungen und das Verhältnis des Physischen zum Psychischen, 6th Edn, Jena: Verlag von Gustav Fischer.

Mates, J., Müller, U., Radil, T., and Pöppel, E. (1994). Temporal integration in sensorimotor synchronization. $J$. Cogn. Neurosci. 6, 332-340.

Meng, M., and Tong, F. (2004). Can attention selectively bias bistable perception? Differences between binocular rivalry and ambiguous figures. J. Vis. 4, 539-551.

Metzinger, T. (2004). Being No One. The Self-Model Theory of Subjectivity. Cambridge : MIT Press.

Miyake, Y., Onishi, Y., and Pöppel, E. (2004). Two types of anticipation in synchronization tapping. Acta Neurobiol. Exp. (Wars) 64, 415-426.

Miyazaki, M., Yamamoto, S., Uchida, S., and Kitazawa, S. (2006). Bayesian calibration of simultaneity in tactile temporal order judgment. Nat. Neurosci. 9, 875-877

Nakajima, Y., Shimojo, S., and Sugita, Y. (1980). On the perception of two successive sound bursts. Psychol. Res. 41, 335-344.

Noulhiane, M., Pouthas, V., and Samson, S. (2008). Is time reproduction sensitive to sensory modalities? Eur. J. Cogn. Psychol. 21, 18-34.

Pastore, R., and Farrington, S. (1996). Measuring the difference limen for identification of order of onset for complex auditory stimuli. Percept. Psychophys. 58, 510-526.

Peterson, L. R., and Peterson, M. J. (1959). Short-term retention of individual verbal items. J. Exp. Psychol. 58, 193-198.

Peters, M. (1989). The relationship between variability of intertap intervals and interval duration. Psychol. Res. 51, 38-42.

Picard, F., and Craig, A. D. (2009) Ecstatic epileptic seizures: a potential window on the neural basis of self-awareness. Epilepsy Behav. 16, 539-546.

Pockett, S. (2003). How long is "now"? Phenomenology and the specious present. Phenomenol. Cogn. Sci. 2 , 55-68.

Poeppel, D. (2003). The analysis of speech in different temporal integration windows: cerebral lateralization as 'asymmetric sampling in time.' Speech Commun. 41, 245-255.

Pöppel, E. (1970). Excitability cycles in central intermittency. Psychol. Res. 34, 1-9.

Pöppel, E. (1978). “Time perception," in Handbook of Sensory Physiology, eds R. Held, W. Leibowitz, and H.-L. Teuber (Berlin: Springer), 713-729.

Pöppel, E. (1988). The measurement of music and the cerebral clock: a new theory. Leonardo 22, 83-89.

Pöppel, E. (1997). A hierarchical model of temporal perception. Trends Cogn. Sci. 1, 56-61.

Pöppel, E. (2009). Pre-semantically defined window for cognitive processing. Philos. Trans. R. Soc. Lond. B Biol. Sci. 364, 1887-1896.

Pöppel, E., Schill, K., and Steinbüchel, N. V. (1990). Sensory integration within temporally neutral system states: a hypothesis. Naturwissenschaften 77, 89-91.

Rattat, A.-C., and Droit-Volet, S. (2011). What is the best and easiest method of preventing counting in different temporal tasks? Behav. Res. Methods doi:10.3758/s13428-011-0135-133. [Epub ahead of print].

Repp, B. H. (2004). On the nature of phase attraction in sensorimotor synchronization with interleaved auditory sequences. Hum. Mov. Sci. 23, 389-413.

Richards, W. (1973). Time reproductions by H. M. Acta. Psychol. 37, 279-282.

Rubin, D. C., and Wenzel, A. E. (1996). One hundred years of forgetting: a quantitative description of retention. Psychol. Rev. 103, 734-760.

Ruhnau, E. (1995). "Time-gestalt and the observer," in Conscious Experience, ed. T. Metzinger (Paderborn: Ferdinand Schöningh), 165-184.

Sacks, O. (1986). The Man Who Mistook his Wife for a Hat. London: Picador.

Scoville, W. B., and Milner, B. (1957). Loss of recent memory after bilateral hippocampal lesions. J. Neurol. Neurosurg. Psychiatr. 20, 11-21.

Staddon, J. E. R. (2005). Interval timing: memory, not a clock. Trends Cogn. Sci. 9, 312-314.

Stern, L. W. (1897). Psychische Präsenzzeit. Z. Psychol. Physiol. Sinnesorg. 13, 325-349.

Stolzenberg, J. (2010). “Zeit und Selbst," in Zum Problem der Zeiterfahrung bei Aristoteles, Augustinus, Husserl und Heidegger, eds $\mathrm{K}$. Crone, $\mathrm{R}$. Schnepf, and J. Stolzenberg (Berlin: Suhrkamp Verlag), 275-301.

Szelag, E., Kanabus, M., Kolodziejczyk, I., Kowalska, J., and Szuchnik, J. (2004). Individual differences in temporal information processing in humans. Acta Neurobiol. Exp. (Wars) 64, 349-366.

Szelag, E., von Steinbüchel, N., Reiser, M., Gilles de Langen, E., and Pöppel, E. (1996). Temporal constraints in processing of nonverbal rhythmic patterns. Acta Neurobiol. Exp. (Wars) 56, 215-225.

Szymaszek, A., Sereda, M., Pöppel, E., and Szelag, E. (2009). Individual differences in the perception of temporal order: the effect of age and cognition. Cogn. Neuropsychol. 26, 135-147.

Thompson, E. (2007). Mind in Life: Biology, Phenomenology, and the Sciences of Mind. Cambridge, MA: Harvard University Press.

Treisman, M. (1963). Temporal discrimination and the difference interval: Implications for a model of the “internal clock." Psychol. Monogr. 77, $1-31$.

Turner, F., and Pöppel, E. (1988). "Metered poetry, the brain, and time," in Beauty and the Brain. Biological Aspects of Aesthetics, eds I. Rentschler, B. Herzberger, and D. Epstein. (Basel: Birkhäuser), 71-90.

Ulbrich, P., Churan, J., Fink, M., and Wittmann, M. (2007). Temporal reproduction: further evidence for two processes. Acta Psychol. (Amst) $125,51-65$ 
Ulbrich, P., Churan, J., Fink, M., and Wittmann, M. (2009). Perception of temporal order: The effects of age, sex, and cognitive factors. Aging Neuropsychol. Cogn. 16, 183-202.

van Ee, R. (2005). Dynamics of perceptual bi-stability for stereoscopic slant rivalry and a comparison with grating, house-face, and Necker cube rivalry. Vision Res. 45, 29-40.

van Wassenhove, V. (2009). Minding time - an amodel representational space for time perception. Philos. Trans. R. Soc. Lond. B Biol. Sci. 364, 1815-1830.

van Wassenhove, V., Grant, K. W., and Poeppel, D. (2005). Visual speech speeds up the neural processing of auditory speech. PNAS 102, 1181-1186.

van Wassenhove, V., Grant, K. W., and Poeppel, D. (2007). Temporal window of integration in auditoryvisual speech perception. Neuropsychologia 45, 598-607.

VanRullen, R., and Koch, C. (2003). Is perception discrete or continuous? Trends Cogn. Sci. 7, 207-213.

Varela, F. J. (1999). Present-time consciousness. J. Consciousness Stud. 6, 111-140.

von Steinbüchel, N., Wittmann, M., and Szelag, E. (1999). Temporal constraints of perceiving, generating, and integrating information: clinical indications. Restor. Neurol. Neurosci. 14, 167-182

Wackermann, J. (2005). "Experience of time passage: phenomenology, psychophysics, and biophysical modelling," in Endophysics, Time, Quantum and the Subjective, eds R. Buccheri, A. C. Elitzur, and M. Saniga (Singapore: World Scientific Publishing), 189-208.

Wackermann, J. (2007). Inner and outer horizons of time experience. Span. J. Psychol. 10, 20-32.

Wackermann, J. (2008). Measure of time: a meeting point of psychophysics and fundamental physics. Mind Matter 6, 9-50.

Wackermann, J., and Ehm, W. (2006). The dual klepsydra model of internal time representation and time reproduction. J. Theor. Biol. 239, 482-493.

Warren, R. M., and Obusek, C. J. (1972). Identification of temporal order within auditory sequences. Percept. Psychophys. 12, 86-90.

White, C. T. (1963). Temporal numerosity and the psychological unit of duration. Psychol. Monogr. 77, 1-37.

Wittmann, M. (2009). The inner experience of time. Philos. Trans. R. Soc. B 364, 1955-1967.

Wittmann, M., Burtscher, A., Fries, W., and von Steinbüchel, N. (2004). Effects of lesion size and location on temporal-order judgment in brain- injured patients. Neuroreport 15 , 2401-2405.

Wittmann, M., and Fink, M. (2004). Time and language - critical remarks on diagnosis and training methods of temporal-order judgement. Acta Neurobiol. Exp. (Wars) 64, 341-348.

Wittmann, M., and Lehnhoff, S. (2005). Age effects in perception of time. Psychol. Rep. 97, 921-935.

Wittmann, M., and Paulus, M. P. (2009). Temporal horizons in decision making. J. Neurosci. Psychol. Econ. 2 $1-11$.

Wittmann, M., and Pöppel, E. (2000). Temporal mechanisms of the brain as fundamentals of communication - with special reference to music perception and performance. Musicae Scientiae Specia Issue 1999-2000, 13-28.

Wittmann, M., Simmons, A. N., Aron, J. L., and Paulus, M. P. (2010). Accumulation of neural activity in the posterior insula encodes the passage of time. Neuropsychologia 48 3110-3120.

Wittmann, M., von Steinbüchel, N. and Szelag, E. (2001). Hemispheric specialisation for self-paced motor sequences. Cogn. Brain Res. 10 341-344.

Yabe, H., Tervaniemi, M., Sinkkonen, J., Huotilainen, M., Ilmoniemi, R. J., and Näätänen, R. (1998). Temporal window of integration of auditory information in the human brain. Psychophysiology 35, 615-619.

Zahavi, D. (2005). Subjectivity and Selfhood: Investigating the First-Person Perspective. Cambridge, MA: MIT Press.

Zakay, D., and Block, R. A. (1997). Temporal cognition. Curr. Dir. Psychol. Sci. 6, 12-16.

Zimbardo, P. G., and Boyd, J. N. (1999). Putting time in perspective: a valid, reliable individual-difference metric. J. Pers. Soc. Psychol. 77, 1271-1288.

Conflict of Interest Statement: The author declares that the research was conducted in the absence of any commercial or financial relationships that could be construed as a potential conflict of interest.

Received: 07 June 2011; paper pending published: 11 July 2011; accepted: 02 October 2011; published online: 18 October 2011.

Citation: Wittmann M (2011) Moments in time. Front. Integr. Neurosci. 5:66. doi 10.3389/fnint.2011.00066

Copyright (c) 2011 Wittmann. This is an open-access article subject to a nonexclusive license between the authors and Frontiers Media SA, which permits use, distribution and reproduction in other forums, provided the original authors and source are credited and other Frontiers conditions are complied with. 